\title{
The short-term effects of a routine poisoning campaign on the movements and detectability of a social top-predator
}

\author{
Benjamin L. Allen • Richard M. Engeman • Luke K-P. Leung
}

Received: 29 May 2013 / Accepted: 29 August 2013 / Published online: 17 September 2013

(C) The Author(s) 2013. This article is published with open access at Springerlink.com

\begin{abstract}
Top-predators can be important components of resilient ecosystems, but they are still controlled in many places to mitigate a variety of economic, environmental and/or social impacts. Lethal control is often achieved through the broadscale application of poisoned baits. Understanding the direct and indirect effects of such lethal control on subsequent movements and behaviour of survivors is an important pre-requisite for interpreting the efficacy and ecological outcomes of toppredator control. In this study, we use GPS tracking collars to investigate the fine-scale and short-term movements of dingoes (Canis lupus dingo and other wild dogs) in response to a routine poison-baiting program as an example of how a common, social top-predator can respond (behaviourally) to moderate levels of population reduction. We found no consistent control-induced differences in home range size or location, daily distance travelled, speed of travel, temporal activity patterns or road/trail usage for the seven surviving dingoes we monitored immediately before and after a typical lethal control event. These data suggest that the spatial behaviour of surviving dingoes was not altered in
\end{abstract}

Responsible editor: Philippe Garrigues

B. L. Allen · L. K. Leung

School of Agriculture and Food Sciences, University of Queensland, Gatton, QLD 4343, Australia

B. L. Allen

Invasive Animals Cooperative Research Centre, Building 22,

University of Canberra, Bruce, Australian Capital Territory 2617,

Australia

R. M. Engeman

National Wildlife Research Centre, US Department of Agriculture, Fort Collins, CO 8051-2154, USA

Present Address:

B. L. Allen $(\bowtie)$

Robert Wicks Pest Animal Research Centre, Biosecurity

Queensland, Toowoomba, QLD 4350, Australia

e-mail: benjamin.allen@daff.qld.gov.au ways likely to affect their detectability, and if control-induced changes in dingoes' ecological function did occur, these may not be related to altered spatial behaviour or movement patterns.

Keywords Behaviourally mediated trophic cascade $\cdot$ Canis lupus dingo $\cdot$ Detection probability $\cdot$ Mesopredator release $\cdot$ Passive tracking index · Poison baiting · Relative abundance indices $\cdot$ Sodium fluoroacetate or 1080

\section{Introduction}

The ecological roles and functions of top-predators can be an important force contributing to ecosystem health and resilience (Estes et al. 2011). Such functions may include the suppression of sympatric mesopredators or prey. In many places, however, top-predator populations are subject to lethal control or harvesting in attempts to mitigate their economic, environmental and/or social impacts, such as predation of livestock or threatened fauna (e.g. Allen et al. 2013a; Mech 2010; Ordiz et al. 2012). Whether undertaken legally or illegally, lethal predator control is often achieved through broadscale distribution of poisoned baits (e.g. Glen et al. 2007b; Márquez et al. 2013). Although a reduction in the density of predators may be the most obvious direct result of lethal control programs, more subtle and indirect outcomes might accompany the removal of individuals from a population, such as spatial and/or temporal changes in space use by survivors (Haber 1996). While top-predator abundances may be resilient to lethal control programs due to compensatory population growth or reinvasion of areas subjected to control (e.g. Allen et al. 2013a; Stahler et al. 2013; Webb et al. 2011), there remains the potential for top-predator populations to be functionally different in these areas due to altered social structures, prey preferences and/or movement behaviours (Haber 1996; Salo et al. 2010). Hence, the behaviour or 
functions of top-predators may change subsequent to lethal control even if top-predator abundance recovers and remains relatively stable over time.

Understanding the direct and indirect effects of lethal control on top-predator populations is an important pre-requisite for interpreting the efficacy and ecological outcomes of toppredator control (Allen et al. 2012; Haber 1996). This understanding is also important for evaluating the reliability of common monitoring techniques used to assess the efficacy of lethal predator control programs, such as population indices or density estimates (Caughley and Sinclair 1994; Hone 2007).

Mesopredator release theory (sensu Soulé et al. 1988; but see Crooks and Soulé 1999) predicts that a reduction in higher-order predator densities can increase densities of lower-order predators - a numerical release. Alternatively or additionally, lethal top-predator control may also result in increased mesopredator activity through altering top-predator behaviour in ways that allow mesopredators to become more active at different times or places in the landscape - a behavioural release (Brown et al. 1999; Clinchy et al. 2013). Mesopredator releases through either mechanism might have detrimental impacts for fauna at lower trophic levels under certain conditions (Crooks and Soulé 1999; Johnson 2006). Much research has focused on indirect patterns in the numerical relationships between top-predators and mesopredators (Ripple et al. 2013; Ritchie and Johnson 2009). However, few studies focus on the actual behavioural responses of top-predators to lethal control, which remains an important research priority (Ordiz et al. 2012; Salo et al. 2010). Some studies sample predators in areas with and without predator control, but when interpreting observed differences between these areas, many studies claim evidence for functional differences in controlled areas without attempting to measure the efficacy of, responses to, or outcomes of lethal control (Salo et al. 2010; but for examples, see Brook et al. 2012; Letnic and Koch 2010). The studies of Eldridge et al. (2002), Kennedy et al. (2012) or Allen et al. (2013a) provide noteworthy exceptions.

Efficacy assessments of lethal predator control programs ideally involve sampling predator populations in otherwise similar treated and untreated areas both before and after a lethal control event or over time (Glen et al. 2007b; Hone 2007). In many cases, sampling is undertaken using relative abundance indices, such as passive tracking indices, scat indices or camera-trap rates (e.g. Allen 2012c; Brook et al. 2012; Engeman 2005; Wang and Fisher 2012). Although comparison of treated and untreated areas is a fundamental experimental design feature necessary for demonstrating the effects of lethal control on the target population (Allen et al. 2013b; Hone 2007; Salo et al. 2010), the utility of relative abundance indices for this purpose relies on the assumption that predator detectability is equal between treatments and remains unchanged by the control program itself (e.g. Archaux et al. 2012; MacKenzie et al. 2006; Pollock et al. 2002). If the control program alters the detectability of surviving predators, then it may be difficult to separate the control-induced numerical responses from behavioural responses, potentially resulting in confounded conclusions about the 'control effect'. That observed index values post-control might reflect either behavioural and/or numerical responses is well known (e.g. Fleming et al. 2001; Kennedy et al. 2012), but there remains a dearth of studies attempting to identify these effects separately. Rare or solitary top-predators experiencing typically low contact rates with conspecifics might be expected to respond indifferently to the loss of conspecifics, whereas common or social top-predators might be expected to respond more strongly.

In this study, we use a widely applicable approach to investigate the behavioural responses of Australian dingoes (Canis lupus dingo and other wild dogs) to a typical poisoning campaign which achieved moderate levels of population reduction. Dingoes are an appropriate model species for this study because they are a common social top-predator routinely exposed to lethal control for the protection of livestock and some threatened species (Fleming et al. 2001). Sodium fluoroacetate is the most common toxin used in poison baits for predator control in Australia; strychnine use has declined remarkably but is still used in some places, and para-aminopropiophenone is presently under consideration for registration as a broad-scale canid control toxin in the near future (APVMA 2008; Fleming et al. 2006; Southwell et al. 2013). Our primary aim was to determine what (if any) behavioural responses might occur following typical lethal control programs using manufactured poison baits. We use GPS tracking collars to investigate spatial and temporal changes in the movements of surviving dingoes. We discuss our results in light of what these changes may mean for fauna at lower trophic levels and for detecting predators using road-based relative abundance or activity indices, such as those commonly used to study dingoes (reviewed in Allen et al. 2013b).

\section{Methods}

Study site and environmental conditions

The study occurred within a $50-\mathrm{km}$ radius of $30^{\circ} 31^{\prime} 33.45^{\prime \prime} \mathrm{S}$, $140^{\circ} 39^{\prime} 37.72^{\prime \prime} \mathrm{E}$ on Quinyambie Station, a $12,000 \mathrm{~km}^{2}$ beef cattle-producing property located in the arid and sandy Strzelecki Desert of northern South Australia. The site has a mean annual rainfall of $\sim 160 \mathrm{~mm}$ (www.bom.gov.au), and landform is comprised of low parallel sand dunes and clay swales (Fitzsimmons 2007). Vegetation is dominated by lowgrowing hopbush (Dodonaea viscosa), buckbush (Salsola kali) and a variety of grasses and burrs including kerosene grass (Aristida spp.) and copperburr (Sclerolaena spp.) (Kutsche and Lay 2003). A substantial amount of previous dingo research has occurred at the site, which includes additional description of the study area (e.g. Allen 2010; Allen et al. 2013a; Allen and Leung 
2012; Brawata and Neeman 2011; Caughley et al. 1980; Letnic and Koch 2010; Newsome et al. 2001; Pople et al. 2000).

Like much of Australia, northern South Australia received record-breaking rainfall between November 2009 and March 2011. Above-average monthly rainfall events occurred multiple times at the site during this period, with approximately 5 years' worth of rainfall occurring over the 12-15 months preceding the study (Fig. 1); the latest significant fall prior to our study occurring in February 2011, which inundated most swales with floodwaters for several weeks. The vegetation response to such high and ongoing rainfall was outstanding, with many extant vegetation types responding positively (B. Allen, personal observations). This facilitated rapid population growth of invertebrates, birds and small mammals, with subsequent increases in dingo activity and abundance during this period (Allen 2011). In chronological order, successive plagues of locusts (Chortoicetes terminifera), beetles, crickets and native (Notomys fuscus) and introduced (Mus musculus) rodents were experienced. Rabbits (Oryctolagus cuniculus) had been in high abundance in 2008 but were reduced to near-undetectable levels by the end of 2009 because of drought (Allen 2010). At the time of the present study, rabbits were distributed across the entire study site but were still in relatively low densities due to recurring bouts of Myxoma virus and Rabbit Haemorrhagic Disease during 2010 (P. Jonas and G. Conners, Quinyambie Station Mangers, pers. comms.). Cattle had not been grazed in the study area since September 2009 , when the site was completely destocked following several severe dust storms at the climax of the drought. The present study began as crickets and rodents (predominately introduced house mice and native dusky hopping-mice) were super-abundant and surface water was readily available, in the latter stages of the annual autumn breeding season for dingoes. Cattle were stocked in areas adjacent to, but not within, the immediate study area during the study period.

\section{Dingo capture, tracking and control}

Dingoes were captured towards the centre of a $1,400 \mathrm{~km}^{2}$ cattle grazing area with soft-catch foot-hold traps (\#3 'Jakes', JC Conner, USA) over three nights in early May 2011 using a variety of lures and decoys. Traps were checked daily both in the late afternoon and in the morning between dawn and $1100 \mathrm{~h}$. Captured dingoes were assessed for trap-related injuries (such as swelling, lacerations, broken or dislocated bones) that might affect their subsequent movement behaviour once released. Standard weights and measures were taken, including age, which was estimated visually from an assessment of tooth wear and breeding status, noting the date of capture and the annual breeding season of dingoes. Captured dingoes were fitted with Sirtrack ${ }^{\circledR}$ Argos-linked GPS datalogging collars $(\sim 450 \mathrm{~g})$ before release. Collars were programmed to record a GPS point each 30 min continuously from the time of activation. To avoid undue human influence on dingo behaviour, no attempts were made to physically locate collared dingoes until after baiting had occurred. On the few occasions when collared dingoes were located, they were approached discretely and were not disturbed. In most cases, collars were recovered several months after the present study period when dingoes were humanely shot from a helicopter.

Not all expected GPS points were obtained (Table 1). Some minor technical errors with some collars on some occasions resulted in variable timing between sequential GPS points, which has the potential to produce unreliable values when calculating travel distances (or the sum of straight line-lengths between sequential GPS points). The GPS data were, therefore, filtered to include only GPS points where the time interval between sequential points was $25-35,55-65,85-95$ or 115-125 min. This meant that only GPS points recorded at $\sim 30$-min intervals were included, allowing for maximum gaps of up to $\sim 2 \mathrm{~h}$ between sequential points. Time gaps over $2 \mathrm{~h}$ were excluded because greater time gaps between GPS points increase the likelihood of underestimating the true distance travelled between sequential GPS points (Rowcliffe et al. 2012). Less than $2.6 \%$ of all the GPS data obtained was excluded by this process. Because the time gap between sequential points still varied between $\sim 30-120 \mathrm{~min}$, we further converted 'travel distance' values to 'speed of travel' (a function of distance and time) to account for the time gaps. These two measures are different but not independent; we report the results for both measures. Positional accuracy of filtered GPS
Fig. 1 Monthly rainfall trends at Quinyambie Station, 2001-2011. Arrow indicates approximate study period

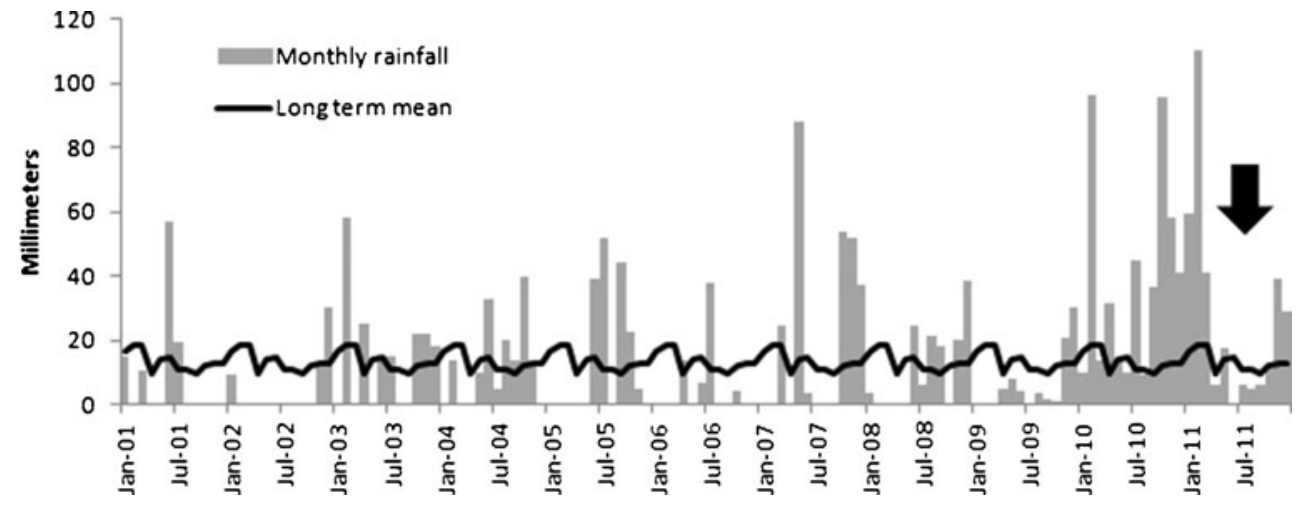




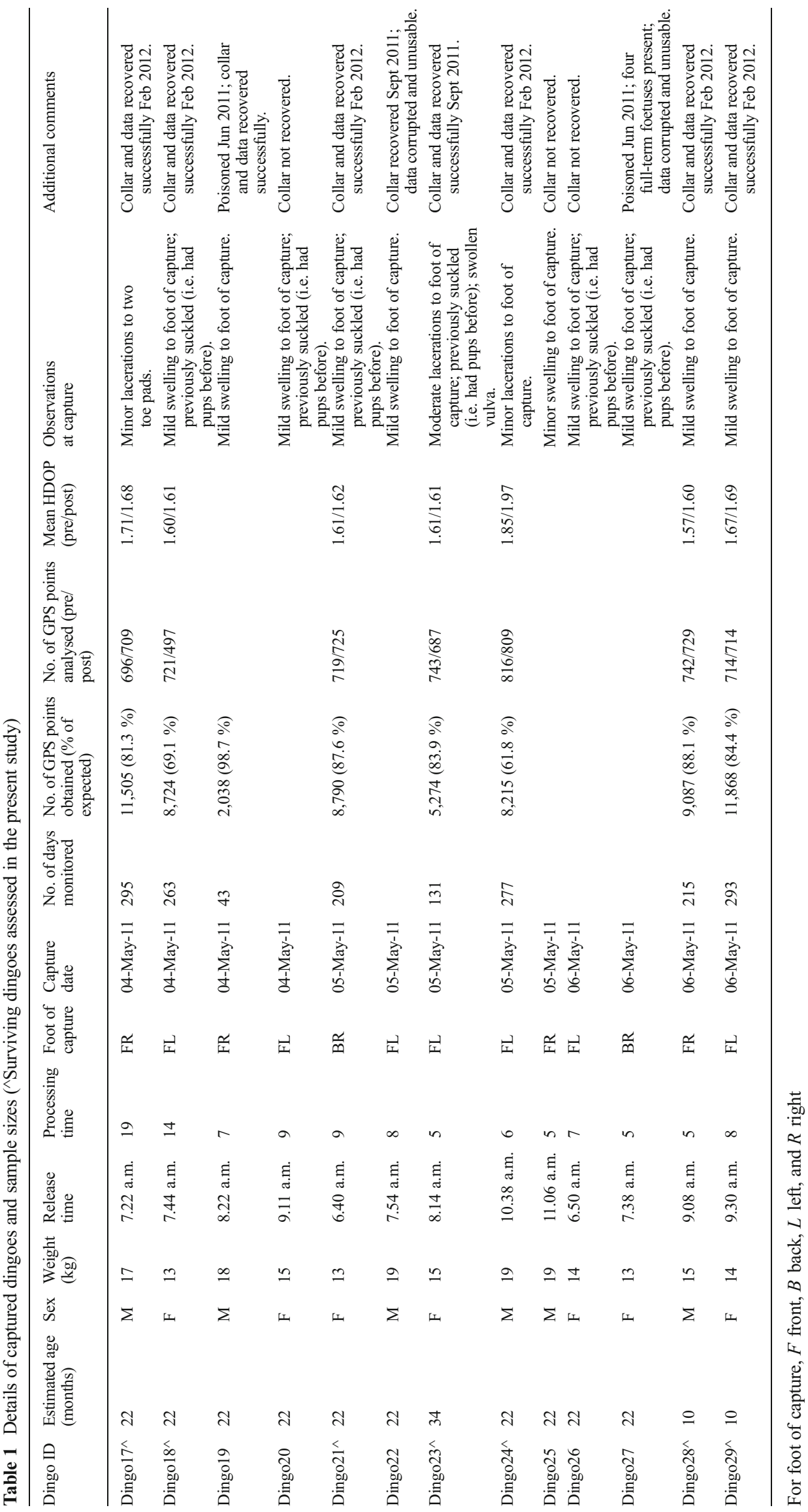


points was assessed using the HDOP values (range 1-15) recorded with each GPS point, with a lower value indicating a more accurate GPS location. Results from the present study were consistent with previous studies at the site, with mean HDOP values ranging between 1.57 and 1.97 (Table 1) or $<50 \mathrm{~m}$ on-ground error (see also Allen 2012a). Hence, all filtered GPS points were considered suitable for inclusion in all analyses, and none were excluded based on HDOP values.

Approximately $65 \%$ of Quinyambie Station (or $\sim 8,000 \mathrm{~km}^{2}$ ) is not baited and is rarely subject to opportunistic shooting. The study was conducted in the southern portion of the property where opportunistic shooting occurs regularly and where baiting has occurred twice each year since March 2008 (Allen 2012b; Allen et al. 2013a). Our study occurred in 2011, when manufactured Doggone ${ }^{\circledR}$-substrate baits were distributed on the 14th and 18th June along all roads and around all livestock watering points within the $1,400 \mathrm{~km}^{2}$ baited area, at a rate of one bait every $300-500 \mathrm{~m}$ according to local practise and poison-use regulations (Bird 1993). Such trail-based baiting practises are typical of those used in most arid and semi-arid areas of the Australian rangelands (Allen et al. 2013a; Fleming et al. 2012). The study period was divided into pre-baiting (28th May-13th June), duringbaiting (14th-30th June) and post-baiting periods (1st-17th July). Bait uptake data indicated that most baits were taken within 17 days after baiting, by the end of the 'during-baiting' period (Allen 2011). Pre- and post-baiting periods were, therefore, limited to equal periods of 17 days duration in order to provide consistent sampling timeframes for analyses, and to minimise any potential influence of seasonal behavioural changes (associated with annual breeding patterns) on the results. Comparisons of movement behaviours were made between pre- and post-baiting periods to avoid the dailychanging circumstances as extant dingoes consumed remaining baits during baiting.

\section{Dingo movements}

Spatial analyses of changes in dingo behaviour and detectability (or the likelihood of a dingo being detected on or near a road) were undertaken in ArcView v9.3 (ESRI Inc.), using the extensions XTools Pro v7.0 (Data East LLC 2005), Hawths Tools v3 (Beyer 2004) and Home Range Tools v3 (Rodgers and Carr 1998).

\section{Home range size changes}

To investigate changes in dingo home range sizes, we compared their mean $100 \%$ minimum convex polygons (MCPs; Harris et al. 1990; Mohr 1947) between pre- and post-baiting periods (i.e. a '17-day home range') using a two-sample twotailed $t$ test (assuming unequal variances). MCPs were chosen over other home range estimators for their ease of calculation, their widespread use for describing dingo home range sizes (e.g. Claridge et al. 2009; Robertshaw and Harden 1985; Thomson et al. 1992), and because we were not concerned with utilisation distributions within the home range for this analysis. We chose $100 \%$ MCPs over $95 \%$ MCPs (or others) because we sought to include all GPS points, and because forays outside the 17-day home range seldom occurred for any dingo during this period (see below). Although calculation of MCPs technically requires the use of independent GPS points (Harris et al. 1990), and our GPS points were not independent, the use of non-independent points seldom changes the resulting MCP values in any substantial way (Gese et al. 1990; Swihart and Slade 1997). Regardless, our primary interest was not in determining the size of the 17-day home range per se, but in detecting relative changes in the size of the home range between pre- and post-baiting periods. For this purpose, the consistent application of any home range estimation technique suffices.

\section{Home range location changes}

To investigate changes in the location of dingo home ranges, we calculated the distance between the centroids of the $100 \%$ MCPs used in the home range size change analyses between pre- and post-baiting periods. We further assessed whether or not these centroids remained within the overall core area of each dingo. Core areas were calculated as the $50 \%$ adaptive kernel (AK; h: 1; Harris et al. 1990; Katajisto and Moilanen 2006; Seaman and Powell 1996) of all GPS points from the time of collaring until the time of death (typically several months; Table 1). Overall home range sizes were similarly calculated as the $90 \%$ AK. The use of AKs was chosen over other home range estimators because, for this analysis, we were concerned with utilisation distributions within the home range, which cannot be identified using MCPs. All the available GPS data for each dingo (from the time of collaring until the time of death) were used to generate AK home range data for this analysis because size and utilisation of home ranges are known to vary seasonally (Allen 2009; Purcell 2010), and using all the available data attempted to capture this variability.

\section{Daily activity period changes}

To investigate changes in the daily activity periods of dingoes, we plotted the overall mean distance travelled (all dingoes pooled) for each hour of the day for both pre- and post-baiting periods. This analysis was repeated using overall mean speed of travel for each hour of the day for both pre- and post-baiting periods. Preliminary results indicated that collared dingoes at the site exhibited three activity peaks at 1700, 000 and $0700 \mathrm{~h}$ (see below), so two-sample two-tailed $t$ tests (assuming unequal variances) were used to identify reductions or increases 
in dingo activity at these dusk, midnight and dawn times between pre- and post-baiting periods.

\section{Daily distance travelled and speed of travel}

To investigate changes in the daily distance travelled by dingoes, we compared the overall mean distance travelled per day (i.e. the mean of the daily sum of line-lengths between sequential GPS points) for the pre- and post-baiting periods using repeated measures ANOVA. The same analysis was performed to assess changes in mean daily speed of travel between periods.

\section{Road or trail usage}

To investigate changes in the time dingoes spent on roads or trails, we compared the mean percentage of GPS points within $250 \mathrm{~m}$ of a road between pre- and post-baiting periods. We further compared the mean percentage of days that roads were contacted between pre- and post-baiting periods. Both analyses were undertaken using repeated measures ANOVA. Considering average dingo travel speeds (see below) and the 30-min duty cycle of the collars, we arbitrarily considered GPS points within $250 \mathrm{~m}$ of a road to reflect road use in order to capture true road use that might otherwise have been 'missed' had road use been restricted to within 100 or $50 \mathrm{~m}$ of a road.

\section{Results}

Dingo capture, tracking and control

A total of 13 dingoes (6 male and 7 female, weighing 13-19 kg) and a 5-kg male red fox (Vulpes vulpes) were captured in 70 trapnights during the 4th-6th May 2011 (Table 1). No other species were inadvertently captured. Each dingo was fitted with a collar and released before 11.15 a.m. the morning after capture. Most dingoes were caught on the front foot, and processing time was typically $<10 \mathrm{~min}$ (median=7 $\mathrm{min}$ ). Ten dingoes were released with minor swelling to the captured paw only, and the three others were released with minor lacerations to the captured paw also (where dingoes had bitten themselves on the toes below the padded jaw of the trap). Such trap-related injuries are common and considered minor (Fleming et al. 1998; Marks et al. 2004). No broken or dislocated bones were observed. Thus, there were no trap-related injuries considered to significantly affect the subsequent movement behaviour of dingoes by the time the pre-baiting period commenced 3 weeks later on the 28th May 2011, nor were these injuries considered to influence the calculation of overall $\mathrm{AK}$ values. Three dingoes (and their collars) could not be located at the conclusion of the study, and two collared dingoes died from bait ingestion in the 'during-baiting' period (Allen 2011). Data from two recovered collars were corrupted and unusable. Thus, seven collared dingoes survived baiting and provided data suitable for analysis (Table 1). Additional bait-efficacy data not reported here demonstrated a $30-40 \%$ reduction in the relative abundance of dingoes depending on how efficacy was measured (Allen 2011). Such reductions are consistent with previous control programs at the study site and elsewhere (Allen et al. 2013a; Fleming et al. 2001; but see Thomson 1986).

\section{Dingo movements}

The 17-day $100 \%$ MCP home range sizes of dingoes ranged between $12.42 \mathrm{~km}^{2}$ (Dingo17) and $194.42 \mathrm{~km}^{2}$ (Dingo28) in the pre-baiting period and $16.65 \mathrm{~km}^{2}$ (Dingo24) and $78.23 \mathrm{~km}^{2}$ (Dingo28) in the post-baiting period (Table 2). Consistent changes in mean home range size were not apparent $(t=0.96, \mathrm{df}=6 ; p=0.37)$; home range sizes increased, decreased or remained unchanged for different dingoes. The distance between home range centroids between the pre- and post-baiting periods ranged from $192 \mathrm{~m}$ for Dingo 21 to just over $40 \mathrm{~km}$ for Dingo28. However, tracking data showed that Dingo28 went on an exploratory foray soon after capture and release, was absent from his home range during the prebaiting period and returned back to his home range during the post-baiting period, giving the misleading impression of a home range shift. Ignoring this extraterritorial foray (the only one observed during the study), the greatest distance between centroids was only $3.01 \mathrm{~km}$. Pre- and post-baiting centroids remained within the $90 \% \mathrm{AK}$ home range of all seven dingoes, and within the $50 \% \mathrm{AK}$ core area of three of these dingoes (Fig. 2), suggesting that despite apparent changes to the location of 17-day $100 \%$ MCPs, no dingo shifted their home range grossly in response to baiting, but rather continued occupying the same home range area.

Dingo activity was highly variable between days over time (Fig. 3), but within days, collared dingoes at our study site exhibited crepuscular peaks of activity at 1700 (dusk) and $0700 \mathrm{~h}$ (dawn) in the pre-baiting period (Fig. 4). Three activity peaks were observed at 1700,000 and $0700 \mathrm{~h}$ in the post-baiting period, suggestive of a behavioural shift from decreased morning to increased night-time activity between early June and early July. No demonstrable changes in dusk activity peaks were observed between pre- and post-baiting periods (for mean distance travelled $t=0.83, \mathrm{df}=7, p=0.43$; for speed of travel $t=$ $0.33, \mathrm{df}=9, p=0.75$ ). Dawn activity peaks were demonstrably lower post-baiting (for mean distance travelled $t=3.06, \mathrm{df}=11$, $p=0.01$; for speed of travel $t=3.35, \mathrm{df}=10, p=<0.00$ ) when activity during the hour after midnight was higher (for mean distance travelled $t=-2.25, \mathrm{df}=9, p=0.05$; for speed of travel $t=$ $-2.20, \mathrm{df}=10, p=0.05$; Fig. 4).

We found no difference in the overall mean daily distance travelled by dingoes between pre- and post-baiting periods $\left(\mathrm{F}_{1,6}=0.26, p=0.63\right)$, the average speed dingoes travelled each day $\left(\mathrm{F}_{1,6}=0.003, p=0.96\right)$, the percentage of GPS points on 
Table 2 Overall home range ( $90 \%$ adaptive kernel) and core area (50\% adaptive kernel) sizes, and changes in the 17 -day $100 \% \mathrm{MCP}$ home range size $\left(\mathrm{km}^{2}\right)$ for seven dingoes in the Strzelecki Desert of northern South Australia between pre- and post-baiting periods in 2011

\begin{tabular}{llllll}
\hline Dingo ID & $90 \% \mathrm{AK}^{\wedge}$ & $50 \% \mathrm{AK}^{\wedge}$ & $100 \% \mathrm{MCP}$ pre* & $100 \% \mathrm{MCP}$ post & Change in $100 \% \mathrm{MCP}$ \\
\hline Dingo17 & 31.51 & 6.56 & 12.42 & 23.48 & $\uparrow 89.05 \%$ \\
Dingo18 & 29.33 & 3.13 & 70.03 & 17.65 & $\downarrow 74.80 \%$ \\
Dingo21 & 18.89 & 2.97 & 24.43 & 22.46 & $\downarrow 8.06 \%$ \\
Dingo23 & 32.23 & 5.21 & 30.02 & 32.50 & $\uparrow 8.26 \%$ \\
Dingo24 & 16.57 & 4.61 & 30.94 & 16.65 & $\downarrow 46.19 \%$ \\
Dingo28 & 286.33 & 28.53 & 194.42 & 78.23 & $\downarrow 59.76 \%$ \\
Dingo29 & 29.77 & 4.17 & 36.33 & 37.98 & $\uparrow 4.54 \%$ \\
Mean & 63.52 & 7.88 & 56.94 & 32.71 & $\downarrow 12.42 \%$ \\
\hline
\end{tabular}

${ }^{\wedge}$ Based on all available data from the time of capture until the time of death, ${ }^{*}$ based on data from the pre-baiting period only and $\sim$ based on data from the post-baiting period only

roads $\left(\mathrm{F}_{1,6}=0.02, p=0.89\right)$ or the percentage of days that roads were contacted $\left(\mathrm{F}_{1,6}=1.28, p=0.30\right.$; Table 3$)$. Despite fine-scale spatial variation in road usage for some dingoes between the preand post-baiting periods (i.e. some dingoes used different sections of the road more or less frequently between periods; Fig. 5), such behaviours did not affect the overall time that dingoes spent on roads or the frequency that roads were contacted. Thus, with the exception of a moderate shift from dawn to night-time activity, all other measures showed no consistently significant change in dingo movement behaviours between pre- and postbaiting periods.

\section{Discussion}

Our study demonstrates that lethal predator control does not influence the movement behaviour of surviving top-predators

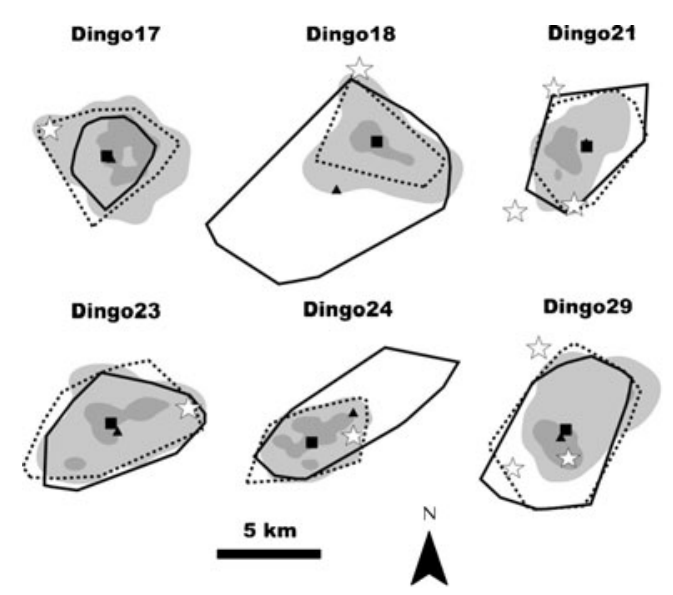

Fig. 2 The overall home range (90\% AK; light grey) and core area (50\% AK; dark grey) sizes of six dingoes in the Strzelecki Desert of northern South Australia in 2011, showing the 17-day $100 \%$ MCP home ranges during the pre-baiting (solid lines) and post-baiting (dashed lines) periods, inclusive of centroids for the $100 \%$ MCPs in the pre-baiting (triangle) and post-baiting (squares) periods. Stars indicate the location of artificial water sources in a consistent manner. Despite moderate population reductions in the order of 30-40\% (Allen 2011), we found no demonstrable or consistent differences in home range size or location (Table 2; Fig. 2), daily distance travelled (Table 3) or road usage (Fig. 5) between the 17-day pre- and post-baiting periods for the seven surviving adult dingoes we monitored. The only change detected was a moderate reduction in dawn activity peaks, coincident with increased night-time activity (Fig. 4). These data reveal no substantial effects of baiting on the movement behaviour of individuals that survived typical levels of lethal control under the conditions present during the study.

Because no data were available from collared dingoes in a paired site not exposed to lethal control, we cannot exclude some plausible alternative explanations for our observations. First, it is possible that normal seasonal changes in dingo activity (associated with whelping) may have masked baiting-induced changes, or have been responsible for the observed shift from dawn to night-time activity. However, dingoes' use of roads typically declines at this time of year (e.g. Allen et al. 2013a; Corbett 2001; Purcell 2010) in preparation for birth and pup-rearing, which means that if baiting did affect dingoes' road use, then it increased it (to the same magnitude as the seasonal reduction), in order for the observed behaviours to appear stable (Fig. 5). Age, season and social status may also affect home range size. However, by the time of breeding in late autumn, all dingoes are approximately 12 months old or older, most juveniles unable to assimilate into a pack have already been killed or expelled, and home range sizes contract to a relatively stable size in preparation for whelping (Allen 2009; Corbett 2001; Fleming et al. 2001; Purcell 2010). Given the relatively short duration of our study conducted at the latter end of the annual breeding season, seasonal factors are unlikely to have influenced our home range size and location analyses in any substantial way. Although individual changes in location of the 17-day $100 \%$ MCP home range were apparent (Table 2), comparison with the overall $90 \% \mathrm{AK}$ home ranges (inclusive of several months of data subsequent to baiting) indicate that home range 

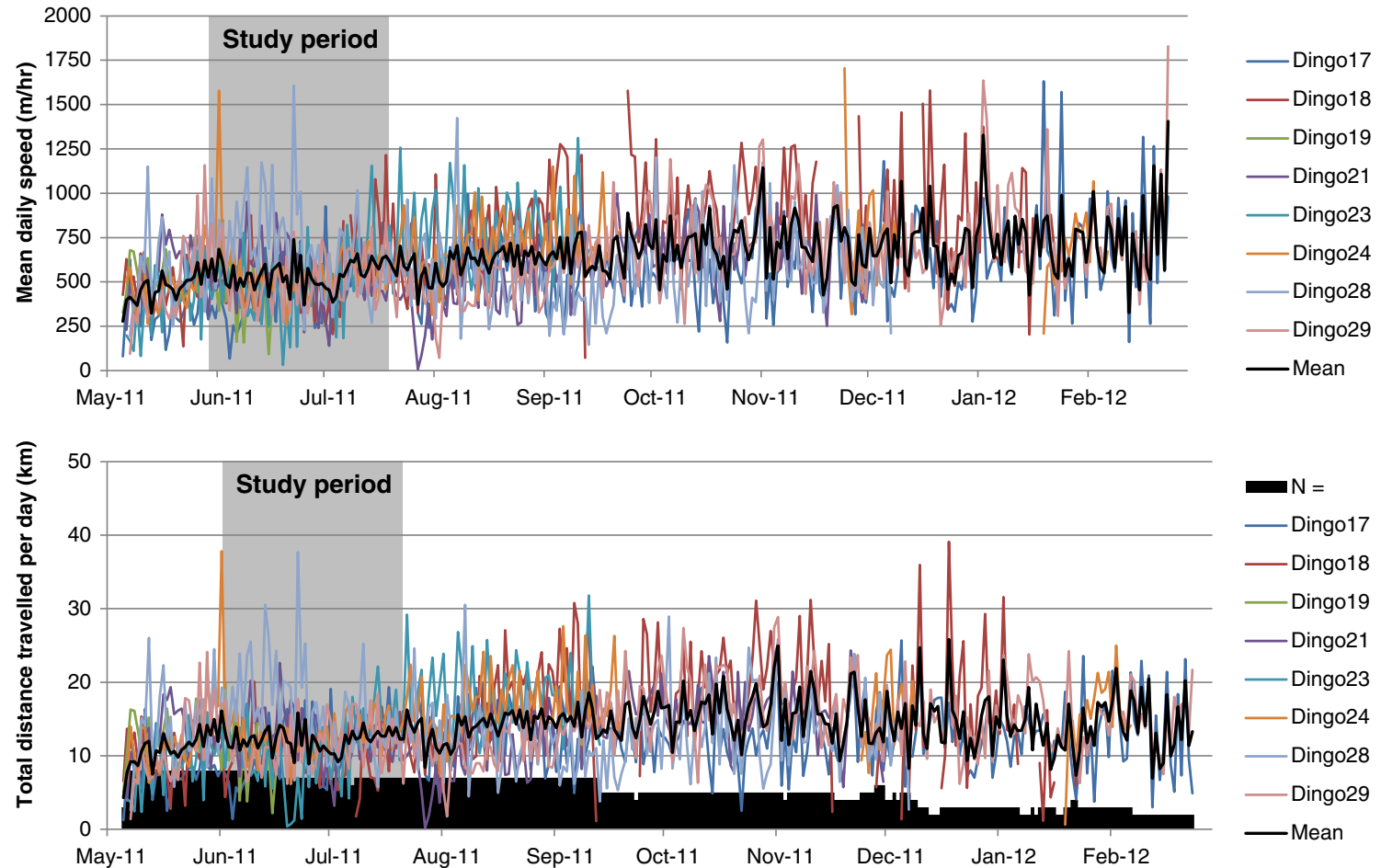

Fig. 3 Daily variation in the mean daily distance travelled (bottom) and mean speed of travel (top) for eight dingoes in the Strzelecki Desert of northern South Australia between May 2011 and February 2012

locations did not shift in response to baiting (Fig. 2). Second, it is possible that rapid reinvasion of uncollared individuals may also have 'filled the hole' in any observed behavioural changes that might have occurred as a result of dingo control. In other words, dingo behaviour might have changed as a result of baiting, but immigrating dingoes moved into the area and prevented the opportunity for resident survivors to alter their behaviour. However, data from a variety of other measures collected simultaneously at the site (e.g. bait uptake data) typically recorded significant reductions in dingo activity on roads (Allen 2011), suggesting that rapid immigration did not occur during the post-baiting period, or that immigrating dingoes avoided roads, which is unlikely (Allen 2009; Corbett 2001; Mahon et al. 1998). Third, and perhaps most likely, given that poison-baiting occurs twice annually at the site, and the dingoes we monitored were typically resident adults (Allen 2012b; Table 1), these individuals have probably been exposed to but not taken baits in the past, and it is conceivable that they have experience with losing conspecifics. In other words, the individual dingoes we monitored may be indifferent to the loss of other related or adjacent dingoes, which may explain the non-responses we observed. Regardless, our results suggest that the overall population-level effect of baiting on dingo behaviour was negligible, and that the movement behaviours of the surviving dingoes we monitored were not altered in consistent ways that may affect their ecological function or detectability.

Though many studies investigate the potential ecological outcomes of lethal dingo control (reviewed in Glen et al. 2007a or Letnic et al. 2012, but see Allen et al. 2013b), few use techniques able to measure the actual behavioural responses of dingoes, such as continuous follows (or direct and continuous first-hand observation), GPS tracking collars or camera traps. Nevertheless, it has been postulated that lethal dingo control results in social destabilisation, with surviving dingo populations being unable to repel expected increases in mesopredator (e.g. fox or feral cat Felis catus) abundance (e.g. Wallach et al. 2009). For example, after pooling singlesurvey camera-trap data across multiple years, seasons and sites, Brook et al. (2012) reported that dingoes occupying baited areas had lower dusk activity levels than dingoes occupying nearby unbaited areas, coincident with higher activity levels of cats at dusk in baited areas. However, an absence of any data on control efficacy or pre- and post-baiting observations meant that the study could not reliably determine actual behavioural shifts of predators to lethal control. In contrast, Wang and Fisher (2012) record a positive spatial relationship between dingoes and cats in baited areas, and negative temporal relationships only at certain times of the year. Only individual dingoes from small and newly formed packs are 
Fig. 4 The daily activity patterns (distance travelled, bottom; speed of travel, top) of seven dingoes in the Strzelecki Desert of northern South Australia during prebaiting (solid line) and postbaiting (dashed line) periods in June-July 2011. Vertical bars indicate standard errors of the mean for each hour
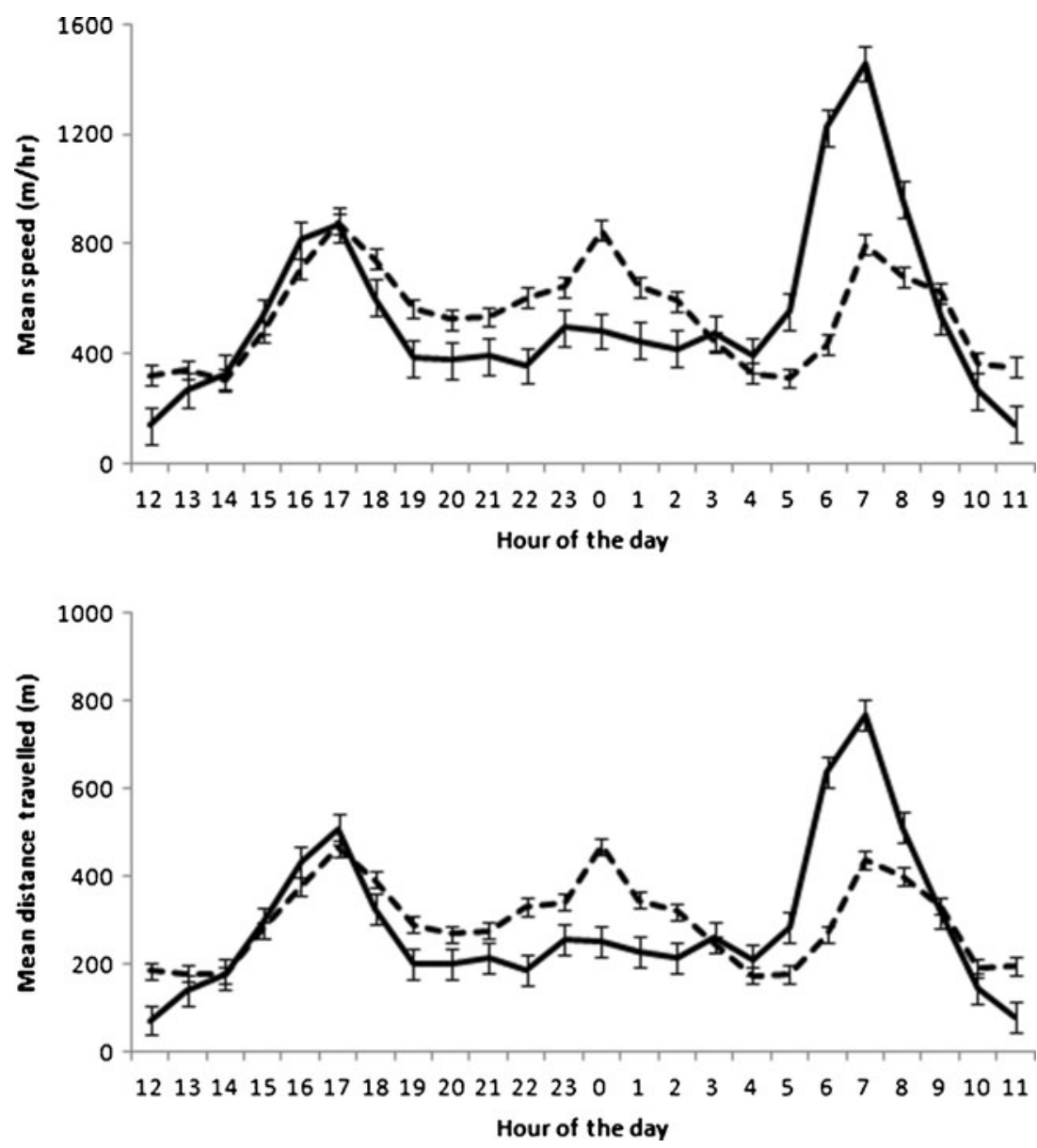

needed to kill invading foxes and feral cats (Moseby et al. 2012), and because we found no change in the mean daily distance travelled by dingoes, the chances of a surviving dingo intercepting invading mesopredators might not be diminished by baiting. Indeed, our GPS tracking data do not show consistent changes in any dingo movement behaviours that would compromise the ability of dingoes to repel mesopredators, such as reduced daily distance travelled, speed of travel, home range size or a shift in home range location (Tables 2 and 3, Figs. 2 and 5).

Dingo activity at dusk did not change as a result of baiting at our site either (Fig. 4), and the observed shift from dawn to night-time activity is most likely due to seasonal effects unrelated to baiting, as dingo populations reach peak whelping times during the post-baiting period in July (Corbett 2001). At this time, dingoes tend to pups in their dens during the colder hours of the morning; dawn temperatures were typically below freezing, and as low as $-6{ }^{\circ} \mathrm{C}$ during the study. This interpretation is supported by several first-hand observations. Dingo 27 (a 13-kg adult female) died from bait ingestion in the duringbaiting period with four fully-grown foetuses just days away from birth (Table 1; Allen 2011). Dingo18 (another 13-kg female that survived baiting) was located resting in her den shortly after dawn on the 7th July when pups only a few days old were observed. Seven pups were later observed and photographed at the entrance of this den on the 2nd and 3rd August. Dingo29 and an uncollared male partner were also located resting in the sun at the entrance of a den shortly after dawn on the 8th July. These observations support the collar data, suggesting that, during whelping, adult dingoes primarily confine their activity within short proximity to (or even in) the den during dawn when temperatures are coldest and pups are most vulnerable to hypothermia.

That the surviving adult dingoes we monitored did not alter their movements consistently in response to lethal control supports a growing body of research indicating that poison baiting programs often target juvenile dingoes or the expendable surplus (e.g. Allen 2013); juveniles contributing relatively little to overall social stability in canids (e.g. Boitani and Ciucci 1995; Corbett 1988; Tallents et al. 2012; Thomson 1992). These observations do not suggest that lethal control changes dingo movement behaviour in ways that would facilitate an increase in mesopredator populations or impacts. A series of conclusive predator-manipulation experiments conducted at 12 sites across Australia (inclusive of the present study site) confirm that contemporary dingo control practises 
Table 3 Changes in daily distance travelled, speed of travel and road usage for seven dingoes in the Strzelecki Desert of northern South Australia between preand post-baiting periods in 2011

\begin{tabular}{llllll}
\hline $\begin{array}{l}\text { Baiting } \\
\text { period }\end{array}$ & $\begin{array}{l}\text { Dingo } \\
\text { ID }\end{array}$ & $\begin{array}{l}\text { Mean distance } \\
\text { travelled per day } \\
(\mathrm{km})\end{array}$ & $\begin{array}{l}\text { Mean speed of } \\
\text { travel per day } \\
(\mathrm{m} / \mathrm{hr})\end{array}$ & $\begin{array}{l}\text { Proportion of } \\
\text { GPS points } \\
\text { on roads }\end{array}$ & $\begin{array}{l}\text { Proportion of } \\
\text { days that roads } \\
\text { were contacted }\end{array}$ \\
\hline Pre & Dingo17 & 7.07 & 307.66 & 0.03 & 0.24 \\
& Dingo18 & 11.46 & 499.61 & 0.35 & 0.76 \\
& Dingo21 & 13.33 & 573.06 & 0.01 & 0.59 \\
& Dingo23 & 11.26 & 489.44 & 0.01 & 0.71 \\
& Dingo24 & 15.51 & 646.55 & 0.02 & 0.94 \\
Pean (SD) & Dingo28 & 18.01 & 757.42 & 0.02 & 0.88 \\
& Dingo29 & 12.70 & 547.42 & 0.11 & 0.88 \\
& & $12.76(3.46)$ & $545.88(140.06)$ & $0.08(0.12)$ & $0.71(0.24)$ \\
& Dingo17 & 12.84 & 550.85 & 0.02 & 0.53 \\
& Dingo18 & 8.14 & 524.95 & 0.16 & 0.88 \\
& Dingo21 & 10.62 & 444.58 & 0.09 & 0.29 \\
& Dingo23 & 12.71 & 587.07 & 0.07 & 0.35 \\
& Dingo24 & 13.90 & 583.93 & 0.08 & 0.65 \\
& Dingo28 & 13.26 & 565.75 & 0.17 & 0.41 \\
& Dingo29 & 12.63 & 539.74 & 0.15 & 0.94 \\
& & $12.01(1.98)$ & $542.41(48.68)$ & $0.11(0.06)$ & $0.58(0.26)$ \\
& & & &
\end{tabular}

do not necessarily result in mesopredator population increases (Allen et al. 2013a).

That road-use by dingoes remained unchanged (e.g. Fig. 5) further suggests that baiting efficacy assessments involving comparisons of road-based relative abundance indices between treatments remain robust, given that detectability of survivors (or the likelihood of a surviving dingo using a road) did not change. Indeed, the percentage of GPS points on roads and the frequency that roads were contacted did not change between pre- and post-baiting periods in our study. However, fine-scale spatial changes in road-use did occur (Fig. 5). Although the lack of a nil-treatment area means that we cannot

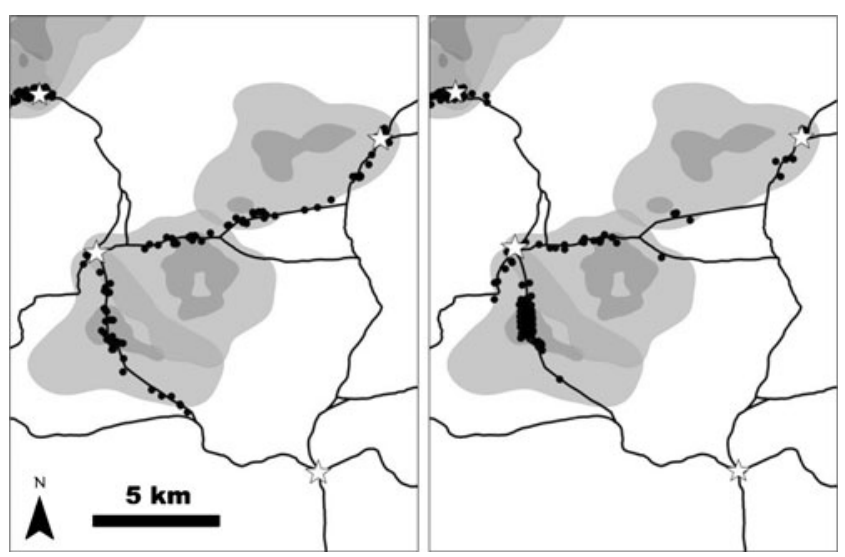

Fig. 5 The overall $90 \%$ AK home range size (light grey) and $50 \%$ AK core area (dark grey) for three dingoes (Dingo23, top; Dingo17, centre; Dingo18, bottom) in the Strzelecki Desert of northern South Australia in 2011. Black dots represent GPS points within $250 \mathrm{~m}$ of roads in the prebaiting (left) and post-baiting (right) periods. Solid lines indicate the location of roads and stars denote water sources be certain that such changes were baiting-induced, this result has important implications for the design of studies that sample dingoes on roads. Sand plots or camera-traps are often placed along roads at $<1,000-\mathrm{m}$ intervals (e.g. Allen et al. 2013a; Catling and Burt 1995; Letnic and Koch 2010); an approach which attempts to maximise the number of sampling points while accounting for logistical constraints and the likely home range size of the study animal. Our results, which suggest that within their home ranges, dingoes use different sections of the road at different times or seasons (as do dingoes elsewhere; Allen 2009), serve as reminder that sand plot or camera-trap sampling must be undertaken in a systematic way at large-enough spatial scales to detect population-level responses of predators to lethal control (Engeman 2005; Glen et al. 2007a). Should the temporal or spatial scale be too small (i.e. too few cameras or sand plots for a given area and period of interest), such studies risk obtaining severely biased results not representative of true population-level responses at larger scales relevant to predator management (Allen et al. 2013b; Allen et al. 2012). Sampling predators off-road is unable to escape this problem of seasonal bias because avoidance of roads in a given season is akin to selection of off-roads in that same season. Considering that there is typically much greater area to place observation stations off-road for sampling activity than on-road, attempting to sample off-roads is also likely to be a highly inefficient means to observe activity, an effect already demonstrated for an ecological analogue of dingoes, the coyote (Canis latrans; Engeman et al. 2002). Dingoes are also known to follow the tracks or paths of humans to off-road sampling stations (B. Allen, P. Fleming, personal observations), confounding attempts to 'hide' the sampling station 
off-road without influencing predator activity. Lethal control also primarily occurs along roads at our study site and in many other places (Allen et al. 2013a; Fleming et al. 2001), which means that changes in animal activity or abundance might be most easily detected and expected to occur in close proximity to roads.

In conclusion, our results provide a useful step forward in our understanding of top-predator responses to lethal control and have important implications for dingo researchers and managers. Our results show that ongoing lethal control programs which remove moderate numbers of dingoes from areas routinely subject to control can fail to produce consistent spatiotemporal behavioural changes of a magnitude that may be necessary to elicit positive responses from mesopredators, and that lethal control does not always change the detectability of surviving dingoes on roads. This implies that should dingo control-induced mesopredator release be observed, it is likely to be a numerical response to lower dingo densities, not a behavioural response to altered dingo movements. Observed changes in predator abundance or activity indices post-baiting are also likely to reflect numerical changes more so than behavioural changes, provided population sampling is undertaken appropriately. Of course, surviving dingoes may respond differently to lethal control programs that achieve greater population reductions than ours, programs conducted in places where extant dingoes have not previously been exposed to lethal control, or programs conducted under different environmental conditions. Thus, there are likely to be cases where the movement behaviour of dingoes will change as a result of lethal control. Whether or not such changes ultimately result in sustained and undesirable outcomes for dingoes or fauna at lower trophic levels requires a much greater understanding of the direct and indirect behavioural effects of control (Allen et al. 2012). We encourage the use of GPS tracking data to explore the behavioural responses of predators to interventions. Such studies may include simultaneous GPS-tracking of sympatric predators exposed to lethal control, and we hope that our findings prompt future research assessing the actual responses of dingoes and other predators to lethal control in comparable ways.

Acknowledgements Greg Conners provided access to the field site. Joseph Allen assisted in the trapping of dingoes, and Simon Cobb and Stuart Boyd-Law assisted in collar recovery. Joe Scanlon, Lee Allen and Matt Gentle provided helpful comments on earlier drafts of the manuscript. The project was undertaken through the Invasive Animals Cooperative Research Centre with funds provided by Meat and Livestock Australia, Australian Wool Innovation and the New South Wales Department of Primary Industries. The study was conducted under approval from an animal ethics committee and the Australian Pesticides and Veterinary Medicines Authority.

Open Access This article is distributed under the terms of the Creative Commons Attribution License which permits any use, distribution, and reproduction in any medium, provided the original author(s) and the source are credited.

\section{References}

Allen BL (2010) Skin and bone: observations of dingo scavenging during a chronic food shortage. Aust Mammal 32:1-2

Allen BL (2011) Efficacy of para-aminopropiophenone (PAPP) to control dingoes (Canis lupus spp.) in the Strzelecki Desert of South Australia: Quinyambie field trial. Animal Control Technologies Australia, Melbourne

Allen BL (2012a) Do desert dingoes drink daily? Visitation rates at remote water points in the Strzelecki Desert. Aust Mammal 34(2): 251-256

Allen BL (2012b) The effect of lethal control on the conservation values of Canis lupus dingo. In: Maia AP, Crussi HF (eds) Wolves: Biology, conservation, and management. Nova Publishers, New York, pp 79-108

Allen BL (2012c) Scat happens: spatiotemporal fluctuation in dingo scat collection rates. Aust J Zool 60(2):137-140

Allen LR (2009) Best practise baiting: dispersal and seasonal movement of wild dogs (Canis lupus familiaris). In: Technical highlights: Invasive plant and animal research 2008-09.' QLD Department of Employment, Economic Development and Innovation, Brisbane, pp 61-62

Allen LR (2013) The impact of wild dog predation and wild dog control on beef cattle: large-scale manipulative experiments examining the impact of and response to lethal control. LAP Lambert Academic Publishing: Saarbrucken, Germany

Allen BL, Leung LK-P (2012) Assessing predation risk to threatened fauna from their prevalence in predator scats: dingoes and rodents in arid Australia. PLoS ONE 7(5):e36426

Allen BL, Fleming PJS, Hayward M, Allen LR, Engeman RM, Ballard G, Leung LK-P (2012) Top-predators as biodiversity regulators: contemporary issues affecting knowledge and management of dingoes in Australia. In: Lameed GA (ed) Biodiversity enrichment in a diverse world. Vol. Chapter 4. InTech Publishing, Rijeka, pp 85-132

Allen BL, Allen LR, Engeman RM, Leung LK-P (2013a) Intraguild relationships between sympatric predators exposed to lethal control: predator manipulation experiments. Front Zool 10:39

Allen BL, Fleming PJS, Allen LR, Engeman RM, Ballard G, Leung LK-P (2013b) As clear as mud: a critical review of evidence for the ecological roles of Australian dingoes. Biol Conserv 159:158-174

APVMA (2008) Review findings for sodium monofluoroacetate: The reconsideration of registrations of products containing sodium monofluoroacetate and approvals of their associated labels, Environmental Assessment. Australian Pesticides and Veterinary Medicines Authority, Canberra

Archaux F, Henry P, Gimenez O (2012) When can we ignore the problem of imperfect detection in comparative studies? Methods Ecol Evol 3(1):188-194

Beyer HL (2004) 'Hawth's analysis tools for ArcGIS.' (Available at www. spatialecology.com/htools)

Bird P (1993) Management plan for buffer baiting Frome border local Dog Fence Board: Quinyambie Station. Animal and Plant Control Commission, SA Department of Water, Land and Biodiversity Conservation, Adelaide

Boitani L, Ciucci P (1995) Comparative social ecology of feral dogs and wolves. Ethol Ecol Evol 7:49-72

Brawata RL, Neeman T (2011) Is water the key? Dingo management, intraguild interactions and predator distribution around water points in arid Australia. Wildl Res 38(5):426-436

Brook LA, Johnson CN, Ritchie EG (2012) Effects of predator control on behaviour of an apex predator and indirect consequences for mesopredator suppression. J Appl Ecol 49(6):1278-1286

Brown JS, Laundre JW, Gurung M (1999) The ecology of fear: optimal foraging, game theory, and trophic interactions. J Mammal 80:385399 
Catling PC, Burt RJ (1995) Studies of the ground-dwelling mammals of eucalypt forests in south-eastern New South Wales: the effect of habitat variables on distribution and abundance. Wildl Res 22:271-288

Caughley G, Sinclair ARE (1994) Wildlife ecology and management. Blackwell Sciences, Cambridge

Caughley G, Grigg GC, Caughley J, Hill GJE (1980) Does dingo predation control the densities of kangaroos and emus? Aust Wildl Res 7(1):1-12

Claridge AW, Mills DJ, Hunt R, Jenkins DJ, Bean J (2009) Satellite tracking of wild dogs in south-eastern mainland Australian forests: implications for management of a problematic top-order carnivore. Forest Ecol Manage 258:814-822

Clinchy M, Sheriff MJ, Zanette LY (2013) The ecology of stress: predatorinduced stress and the ecology of fear. Funct Ecol 27(1):56-65

Corbett LK (1988) Social dynamics of a captive dingo pack: population regulation by dominant female infanticide. Ethology 78:177-198

Corbett LK (2001) The dingo in Australia and Asia, Secondth edn. J.B. Books, South Australia, Marleston

Crooks KR, Soulé ME (1999) Mesopredator release and avifaunal extinctions in a fragmented system. Nature 400:563-566

Data East LLC (2005) 'XTools Pro extension for ArcGIS.' (Available at www.xtoolspro.com: Novosibirsk, Russia)

Eldridge SR, Shakeshaft BJ, Nano TJ (2002) The impact of wild dog control on cattle, native and introduced herbivores and introduced predators in central Australia, Final report to the Bureau of Rural Sciences. Parks and Wildlife Commission of the Northern Territory, Alice Springs

Engeman R (2005) Indexing principles and a widely applicable paradigm for indexing animal populations. Wildl Res 32(3):202-210

Engeman R, Pipas M, Gruver K, Bourassa J, Allen L (2002) Plot placement when using a passive tracking index to simultaneously monitor multiple species of animals. Wildl Res 29(1):85-90

Estes JA, Terborgh J et al (2011) Trophic downgrading of planet earth. Science 333:301-306

Fitzsimmons KE (2007) Morphological variability in the linear dunefields of the Strzelecki and Tirari Deserts, Australia. Geomorphology 91(1-2): 146-160

Fleming PJ, Allen LR, Berghout MJ, Meek PD, Pavlov PM, Stevens PL, Strong K, Thompson JA, Thomson PC (1998) The performance of wild-canid traps in Australia: efficiency, selectivity, and trap-related injuries. Wildl Res 25(3):327-338

Fleming P, Corbett L, Harden R, Thomson P (2001) Managing the impacts of dingoes and other wild dogs. Bureau of Rural Sciences, Canberra

Fleming PJS, Allen LR, Lapidge SJ, Robley A, Saunders GR, Thomson PC (2006) Strategic approach to mitigating the impacts of wild canids: proposed activities of the Invasive Animals Cooperative Research Centre. Aust J Exp Agric 46(6-7):753-762

Fleming PJS, Allen BL, Ballard G, Allen LR (2012) Wild dog ecology, impacts and management in northern Australian cattle enterprises: a review with recommendations for R, D\&E investments. Meat and Livestock Australia, Sydney

Gese EM, Andersen DE, Rongstad OJ (1990) Determining home-range size of resident coyotes from point and sequential locations. J Wildl Manag 54(3):501

Glen AS, Dickman CR, Soulé ME, Mackey BG (2007a) Evaluating the role of the dingo as a trophic regulator in Australian ecosystems. Austral Ecol 32(5):492-501

Glen AS, Gentle MN, Dickman CR (2007b) Non-target impacts of poison baiting for predator control in Australia. Mammal Rev 37(3):191-205

Haber GC (1996) Biological, conservation and ethical implications of exploiting and controlling wolves. Conserv Biol 10(4):1068-1081

Harris S, Cresswell WJ, Forde PG, Trewhella WJ, Woollard T, Wray S (1990) Home range analysis using radio-tracking data: a review of problems and techniques particularly as applied to the study of mammals. Mammal Rev 20(2-3):97-123
Hone J (2007) Wildlife damage control. CSIRO Publishing, Collingwood, Victoria

Johnson C (2006) Australia's mammal extinctions: a 50,000 year history. Cambridge University Press, Melbourne

Katajisto J, Moilanen A (2006) Kernel-based home range method for data with irregular sampling intervals. Ecol Model 194:405-413

Kennedy M, Phillips B, Legge S, Murphy S, Faulkner R (2012) Do dingoes suppress the activity of feral cats in northern Australia? Austral Ecol 37(1):134-139

Kutsche F, Lay B (2003) Field guide to the plants of outback South Australia. Department of Water, Land and Biodiversity Conservation, Government of South Australia, Adelaide

Letnic M, Koch F (2010) Are dingoes a trophic regulator in arid Australia? A comparison of mammal communities on either side of the dingo fence. Austral Ecol 35(2):167-175

Letnic M, Ritchie EG, Dickman CR (2012) Top predators as biodiversity regulators: the dingo Canis lupus dingo as a case study. Biol Rev 87(2):390-413

MacKenzie DI, Nichols JD, Royle JA, Pollock KH, Bailey LL, Hines JE (2006) Occupancy estimation and modelling: Inferring patterns and dynamics of species occurrence. Academic Press (Elsevier), London

Mahon PS, Banks PB, Dickman CR (1998) Population indices for wild carnivores: a critical study in sand-dune habitat, south-western Queensland. Wildl Res 25:11-22

Marks CA, Allen L, Gigliotti F, Busana F, Gonzalez T, Lindeman M, Fisher PM (2004) Evaluation of the trap tranquiliser device (TTD) for improving the humaneness of dingo trapping. Anim Welf 13: 393-399

Márquez C, Vargas JM, Villafuerte R, Fa JE (2013) Understanding the propensity of wild predators to illegal poison baiting. Anim Conserv 16(1):118-129

Mech LD (2010) Considerations for developing wolf harvesting regulations in the contiguous United States. J Wildl Manag 74(7):14211424 [In English]

Mohr CO (1947) Table of equivalent populations of North American small mammals. Am Midl Nat 37(1):223-249

Moseby KE, Neilly H, Read JL, Crisp HA (2012) Interactions between a top order predator and exotic mesopredators in the Australian rangelands. Int J Ecol Article ID 250352, 15 pages

Newsome AE, Catling PC, Cooke BD, Smyth R (2001) Two ecological universes separated by the dingo barrier fence in semi-arid Australia: interactions between landscapes, herbivory and carnivory, with and without dingoes. Rangel J 23(1):71-98

Ordiz A, Støen O-G, Sæbø S, Kindberg J, Delibes M, Swenson JE (2012) Do bears know they are being hunted? Biol Conserv 152:21-28

Pollock KH, Nichols JD, Simons TR, Farnsworth GL, Bailey LL, Sauer JR (2002) Large-scale wildlife monitoring studies: statistical methods for design and analysis. Environmetrics 13(2):105-119

Pople AR, Grigg GC, Cairns SC, Beard LA, Alexander P (2000) Trends in the numbers of red kangaroos and emus on either side of the South Australian dingo fence: evidence for predator regulation? Wildl Res 27:269-276

Purcell BV (2010) Dingo. Australian Natural History Series. CSIRO Publishing, Collingwood

Ripple WJ, Wirsing AJ, Wilmers CC, Letnic M (2013) Widespread mesopredator effects after wolf extirpation. Biol Conserv 160:70-79

Ritchie EG, Johnson CN (2009) Predator interactions, mesopredator release and biodiversity conservation. Ecol Lett 12(9):982-998

Robertshaw JD, Harden RH (1985) The ecology of the dingo in northeastern New South Wales, I. Movement and home range. Aust Wildl Res 12(1):25-37

Rodgers AR, Carr AP (1998) HRE: The Home Range Extension for ArcView. Ontario Ministry of Natural Resources, Centre for Northern Forest Ecosystem Research, Thunder Bay 
Rowcliffe JM, Carbone C, Kays R, Kranstauber B, Jansen PA (2012) Bias in estimating animal travel distance: the effect of sampling frequency. Methods Ecol Evol 3(4):653-662

Salo P, Banks PB, Dickman CR, Korpimaki E (2010) Predator manipulation experiments: impacts on populations of terrestrial vertebrate prey. Ecol Monogr 80(4):531-546

Seaman DE, Powell RA (1996) An evaluation of the accuracy of kernel density estimators for home range analysis. Ecology 77(7):20752085

Soulé ME, Bolger DT, Alberts AC, Sauvajot RS, Wright J, Sorice M, Hill S (1988) Reconstructed dynamics of rapid extinctions of chaparralrequiring birds in urban habitat islands. Conserv Biol 2(1):75-92

Southwell D, Boero V, Mewett O, McCowen S, Hennecke B (2013) Understanding the drivers and barriers to participation in wild canid management in Australia: implications for the adoption of a new toxin, para-aminopropiophenone. Int J Pest Manag 59(1), 35-46

Stahler DR, MacNulty DR, Wayne RK, vonHoldt B, Smith DW (2013) The adaptive value of morphological, behavioural and life-history traits in reproductive female wolves. J Anim Ecol 82(1):222-234

Swihart RK, Slade NA (1997) On testing for independence of animal movements. J Agric Biol Environ Stat 2(1):48-63
Tallents LA, Randall DA, Williams SD, Macdonald DW (2012) Territory quality determines social group composition in Ethiopian wolves Canis simensis. J Anim Ecol 81(1):24-35

Thomson PC (1986) The effectiveness of aerial baiting for the control of dingoes Canis familiaris dingo in north-western Australia. Aust Wildl Res 13(2):165-176

Thomson PC (1992) The behavioural ecology of dingoes in northwestern Australia: IV. Social and spatial organisation, and movements. Wildl Res 19(5):543-563

Thomson PC, Rose K, Kok NE (1992) The behavioural ecology of dingoes in north-western Australia: VI. Temporary extraterritorial movements and dispersal. Wildl Res 19(5):585-595

Wallach AD, Ritchie EG, Read J, O'Neill AJ (2009) More than mere numbers: the impact of lethal control on the stability of a top-order predator. PloS ONE 4(9):e6861

Wang Y, Fisher D (2012) Dingoes affect activity of feral cats, but do not exclude them from the habitat of an endangered macropod. Wildl Res 39:611-620

Webb NF, Allen JR, Merrill EH (2011) Demography of a harvested population of wolves (Canis lupus) in west-central Alberta, Canada. Can J Zool 89(12):744-752 